\title{
Configural learning, spatial navigation, and amphetamine-induced activity spared with ibotenic acid but not quinolinic acid lesions of the dorsomedial thalamus in rats
}

\author{
JO-ANNE TOMIE and IAN Q. WHISHAW \\ University of Lethbridge, Lethbridge, Alberta, Canada
}

\begin{abstract}
The connections that the dorsomedial (MD) thalamus makes with the frontal cortex and hippocampus suggest that it should share in their functions. This study examined the role of the dorsomedial nucleus (MD) of the thalamus in learning tasks that require the use of compound cues and in amphetamine-induced locomotion. The cell-specific neurotoxins ibotenic acid and quinolinic acid were injected into $\mathrm{MD}$, and the animals were tested on a configural tactile-olfactory task, on a matching-toplace task in a swimming pool, and on spontaneous and amphetamine-induced locomotion. The ibotenic acid lesions produced cell death that was relatively confined to $\mathrm{MD}$, while the quinolinic acid lesions produced widespread thalamic cell death and calcium deposits. The control and the ibotenic acid groups were not different, but the quinolinic acid lesions produced significant impairments on all of the tasks. The results suggest that although the frontal cortex and hippocampus may participate in solving the tasks used in this study, the MD, despite its reciprocal connections, does not share their involvement. The quinolinic acid results suggest either that very large lesions are required to produce deficits or that other thalamic nuclei are involved in the behaviors that were measured.
\end{abstract}

The purpose of the present study was to examine the role of the dorsomedial nucleus of the thalamus (MD) in learning tasks that require the use of compounds. This kind of learning is of special interest because, in using multiple stimuli, animals must suppress response tendencies to, or associations with, individual stimulus items. Configural tasks (Sutherland \& Rudy, 1989) and spatial tasks (O'Keefe \& Nadel, 1978) are examples of tasks in which the use of compounds is essential. In configural tasks (Sutherland \& Rudy, 1989), each of the stimulus items are positively and negatively reinforced equally, so the items themselves provide no cue to the solution of the task. In an exemplar configural olfactory-tactile task (Whishaw \& Tomie, 1991; Whishaw, Tomie, \& Kolb, 1992), rats are required to pull up strings to obtain attached pieces of food. The strings vary in size and can be baited with an odor so that the animals must attend to both tactile and olfactory cues to learn the task. Forms of spatial learning in which animals acquire place responses to targets that are hidden similarly demand the use of relational properties of at least two stimuli and, in this sense, can also be called configural. The Morris swimming-pool place task (Morris, 1981), in which animals must escape from water by swimming to a platform hidden just beneath the surface of the water, is a

This research was supported by a grant from the Canadian Natural Sciences and Engineering Research Council. J.T. was supported by a grant from the Alberta Heritage Foundation for Medical Research. Correspondence should be directed to I. Q. Whishaw, Department of Psychology, University of Lethbridge, Lethbridge, AB, Canada T1K 3M4 (e-mail: whishaw@hg.uleth.ca). widely used place task for rodents. In matching-to-place versions (Whishaw, 1985), animals are required to learn a new place response each day, thus mitigating the possibility that they can use a single cue as a beacon or landmark.

Since configural and spatial tasks both require the use of compounds, it has been proposed that they are mediated by similar neural structures and by ones that are different from those that mediate cue learning (Rudy \& Sutherland, 1992; Sutherland \& Rudy, 1989). A candidate system is Petri and Mishkin's (1994) "memory" system, which includes temporal limbic cortex (rhinal areas, hippocampus, and amygdala), frontal limbic cortex (orbital frontal cortex), and the medial thalamus. It has been demonstrated that lesions to the hippocampus impair place learning (Whishaw, 1987; Whishaw, Cassel, \& Jarrard, 1995) and orbital frontal cortex lesions impair acquisition or retention of the configural tactile-olfactory string task (Whishaw \& Tomie, 1991) and place learning (Corwin, Fussinger, Meyer, King, \& Reep, 1994). Thus, these results are consistent with the idea that at least portions of this circuit mediate learning that involves cue compounds.

The role of MD in learning compounds is uncertain. Clinical studies (Graff-Radford, Tranel, Van Hoesen, \& Brandt, 1990; Squire \& Moore, 1979; Victor, Adams, \& Collins, 1971), experimental studies in nonhuman primates (Aggleton \& Mishkin, 1983a, 1983b; Zola-Morgan \& Squire, 1985), and studies with rodents (Delacour, 1971; Kolb, 1977; M'Harzi, Jarrard, Willig, Palacios, \& Delacour, 1991; Mumby, Pinel, \& Dastur, 1993; Stokes \& Best, 1990a, 1990b; Tinger, 1974; Winocur, 1985) all suggest that MD 
is involved in learning. MD also relays olfactory projections to the orbital frontal cortex (Benjamin \& Jackson, 1974; Heimer, 1972), and damage to MD in rats impairs some forms of olfactory learning (Eichenbaum, Shedlack, \& Eckmann 1980; Slotnick \& Kaneko, 1981; Staubli, Schottler, \& Nejat-Bina, 1987). Although we have previously reported that acquisition of a single place response in the swimming pool is not impaired by MD lesions (Kolb, Pittman, Sutherland, \& Whishaw, 1982), there are reports of spatial impairments following MD lesions in dry-land mazes (Kessler, Markowitsch, \& Otto, 1982; M'Harzi et al., 1991; Stokes \& Best, 1990a, 1990b). To this point, there have been no explicit tests to examine the role of MD in configural tasks or in matching-to-place tasks.

To examine the possible role of MD in learning tasks involving cue compounds, rats were given ibotenic acid or quinolinic acid neurotoxic lesions to damage the cells of $\mathrm{MD}$, and were tested on acquisition and retention of a configural tactile-olfactory task and in a matching-to-place spatial task. To assess any nonspecific effects of the lesions, the rats were also tested for locomotor activity in spontaneous and amphetamine-induced tests. This additional test was conducted because MD has connections with basal ganglia structures (Alexander, Crutcher, \& DeLong, 1990 ) and is suggested to contribute to locomotor activity (Mogenson, Jones, \& Yim, 1980), and because damage to its target areas in the frontal cortex results in increased spontaneous (Richter, 1976) and amphetamine-induced locomotion (Lynch, Ballantine, \& Campbell, 1969).

\section{METHOD}

\section{Subjects}

The subjects were 52 adult, female Long-Evans hooded rats from the University of Lethbridge (Lethbridge, Alberta, Canada) vivarium, which weighed $200-250 \mathrm{~g}$ when the study began. They were housed in an animal colony maintained on a $12: 12$-h light:dark cycle with room temperature set at $21^{\circ}-22^{\circ} \mathrm{C}$. Testing was done during the light portion of the cycle. Before testing began, feeding was restricted so that the rats were gradually reduced to, and maintained at, $80 \%-90 \%$ of expected body weight. Wayne Rodent pellets were used for supplemental feeding to maintain body weight throughout the test period.

\section{Surgery}

For surgery, the rats were anesthetized with intraperitoneal injections of sodium pentobarbital $(40 \mathrm{mg} / \mathrm{kg}$ ) and atropine methylnitrate $(5 \mathrm{mg} / \mathrm{kg})$. Lesions were made by infusing solutions containing either $0.3 \mu \mathrm{g}$ of ibotenic acid $(10 \mu \mathrm{g} / \mu \mathrm{l}$ dissolved in $1 \mathrm{M}$ phosphate buffered saline, $\mathrm{pH}=7.4)$ or $0.01 \mu \mathrm{g}$ of quinolinic acid $(0.02 \mu \mathrm{g} / \mu \mathrm{l}$ dissolved in $1 \mathrm{M}$ phosphate buffered saline, $\mathrm{pH}=7.4$ ) through a 30 -ga stainless steel cannula. Two different neurotoxins were used because there is extensive evidence to indicate that the specificity of the toxins for cell populations varies (Dunnett, Whishaw, Jones, \& Bunch, 1987). To date, there have been no parametric studies on toxicity and the thalamus, but the finding here that quinolinic lesions produced more widespread damage than ibotenic acid lesions recommended that the results from both toxins be included here. Using a 10- $\mu 1$ Hamilton microsyringe attached to an automated infusion pump, the solutions were infused at a rate of $0.1 \mu \mathrm{l} / \mathrm{min}$. With bregma and lambda on the same horizontal plane, coordinates for placement of the cannula, measured in relation to bregma, the midline, and the dura, were
$2.7 \mathrm{~mm}$ posterior, $1.0 \mathrm{~mm}$ lateral, and $5.0 \mathrm{~mm}$ ventral. After infusions, the cannula were left in place for $5 \mathrm{~min}$ to allow for diffusion.

\section{Configural Task}

\section{Configural Test Apparatus}

The configural test stand (Tomie \& Whishaw, 1990) was a $24 \times$ $15.5 \mathrm{~cm}$ Plexiglas platform with $13-\mathrm{cm}$-high walls lining its sides and back (Figure 1). The platform was mounted on a $41-\mathrm{cm}$-high pedestal. A 3-mm-diam metal bar was attached to the front of the platform $12 \mathrm{~cm}$ above its floor. Strings with food pellets tied onto their distal ends could be attached with alligator clips to the metal bar (see Figure 1).

\section{Food Pellets}

Food pellets were 190-mg dustless precision rodent pellets (BioServ, Incorporated, Frenchtown, NJ).

\section{Tactile Stimuli}

Small- and large-diameter strings, $50 \mathrm{~cm}$ long, were the tactile stimuli. The strings were made by using a simple fringe method (Harvey, 1967) of twisting strands of fine cotton household twine together in one direction, folding the twisted strands in half, and then twisting the folded strands together in the opposite direction. An overhand knot was tied into one end, and an alligator clip was attached to the other end. The number of strands of twine twisted together determined string size, with small strings (T1) consisting of 2 strands and large strings (T2) consisting of 10 strands. Uniform string sizes were obtained by using premeasured lengths of strings and equivalent numbers of wraps. This method produced strings with average widths of $1 \mathrm{~mm}$ for small strings and $5 \mathrm{~mm}$ for large strings. When a rat pulled up a string, it received a food pellet that was inserted into a loosely tied overhand knot at the end of the string. A large number of strings were prepared so that the strings could be changed every few days throughout pretraining and testing. This procedure was used to ensure that the rats were not using some nonrelevant feature of an individual string as a cue to direct their choices.

\section{Olfactory Stimuli}

Almond extract was used as an odor cue, and the odor was either present $(\mathrm{O} 1)$ or absent $(\mathrm{O} 2)$. A piece of Elastoplast fabric adhesive tape, $2.5 \mathrm{~cm}$ wide and $5 \mathrm{~cm}$ long (Smith and Nephew, Inc., Lachine, Quebec, Canada, Ref. 1001), was wrapped around the strings (Figure 1). The length of the tape was varied slightly so that the exposed surface of the tape was the same for each string size. The tape was either painted lightly with almond extract or was left unpainted. The extract evaporates overnight so the same string could be either an odor-positive or an odor-negative cue, depending on whether or not the odor was freshly painted onto the tape.

\section{Swimming Pool}

The swimming pool was a circular tank, $146 \mathrm{~cm}$ in diameter and $46 \mathrm{~cm}$ high, that was painted white and filled to a height of $25 \mathrm{~cm}$ with $18^{\circ} \mathrm{C}$ water (Whishaw, 1985). Approximately $1,500 \mathrm{ml}$ of skimmed milk powder was dissolved in the water to make it opaque. A clear Plexiglas platform $(14 \times 14 \mathrm{~cm})$ was submerged $14 \mathrm{~mm}$ below the water surface and was invisible to the rats when they were inside the pool.

\section{Activity Cages}

Locomotor activity was tested in a bank of 16 wire photocell cages (Whishaw, Rod, \& Auer, 1994). The individual cages were $40 \mathrm{~cm}$ long, $25 \mathrm{~cm}$ deep, and $14 \mathrm{~cm}$ high, with two parallel horizontal infrared beams $1 \mathrm{~cm}$ above the floor, $34 \mathrm{~cm}$ apart, and perpendicular to the long axis of the cage. The beam breaks, registered incrementally via a microcomputer, were counted by the microcomputer as left-beam breaks and right-beam breaks. Cage crosses, abstracted 
A

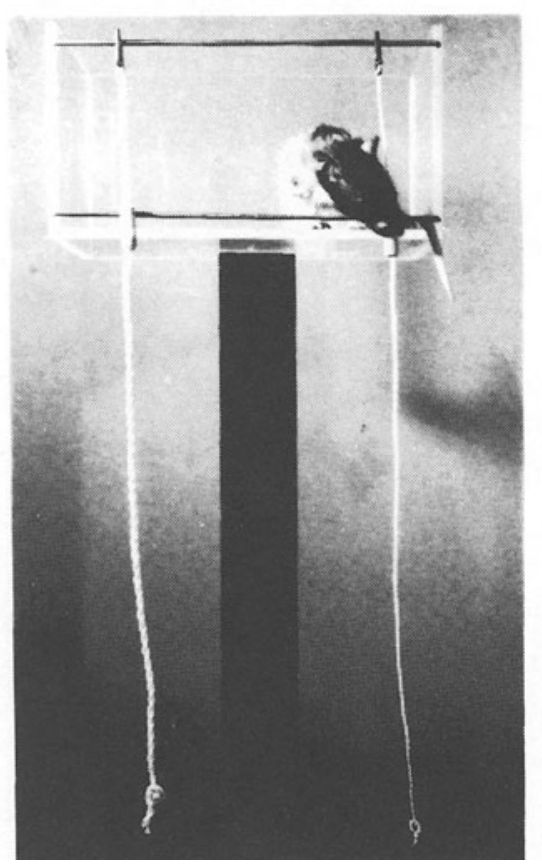

B

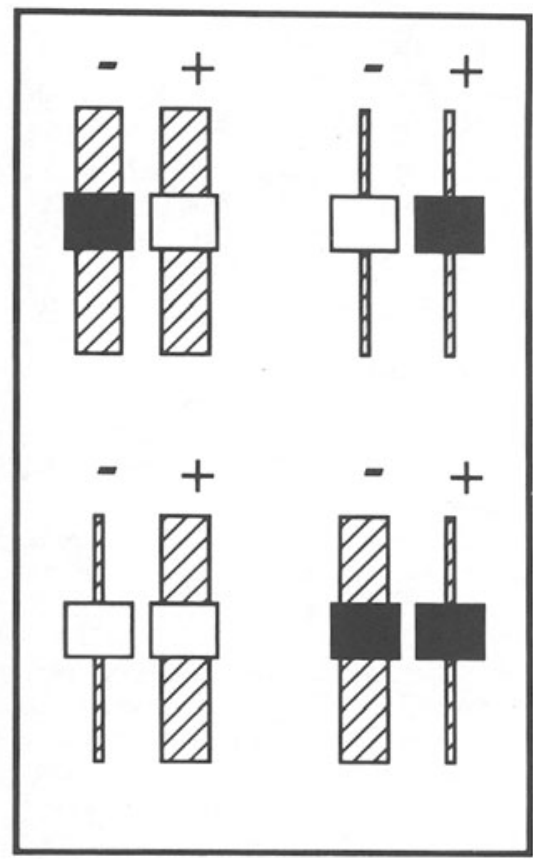

Figure 1. (A) A rat on the string-pulling stand. The thick string, on the left, has food tied onto its distal end. The rat determines which string has food by attending to the thickness of the strings and to the odor painted on pieces of tape attached to the strings. In this photograph, the rat is sniffing the tape attached to the string that does not contain food. (B) Schematic illustration of the configural task. The hatched rectangles indicate the two diameters of string. The black and white boxes indicate the almond-scented tape (black) or plain tape (white). In a simple association and its reversal, the animal learns that scented is either correct $(+)$ or incorrect $(-)$ (e.g., learn top left then top right). In the configural task, an animal must perform all four of the discriminations concurrently.

from the photocell counts, were used as the measure of walking. A cross comprised a return trip along the length of the cage and three alternating beam interruptions (e.g., left, right, left). Cage crosses were summed at 10 -min bins.

\section{Procedure}

\section{Configural Task}

Twenty-eight rats were used for the configural task: 14 control, 7 with ibotenic acid, and 7 with quinolinic acid lesions of the mediodorsal nucleus of the thalamus.

Pretraining. The rats were pretrained by being placed individually on the test stand for 10 to $15 \mathrm{~min}$ each day. Using a successive approximation operant conditioning procedure, the rats were trained to pull up a medium-size ( $2.5 \mathrm{~mm}$ wide) string to obtain food. After each correct response, the string was removed, another food pellet was placed on its end, and the string was replaced. Within 7 days, the rats were adept at string pulling. During the next week, the rats were required to pull up a variety of different-size strings, presented in random order. This procedure was used because rats that have been pretrained with only one size of string subsequently reject novel sizes when a discrimination problem is first presented.

Response criteria and analysis. A trial consisted of the simultaneous presentation of two strings, which were separated by $15 \mathrm{~cm}$. Only one string had food tied to it. When a rat pulled up the string with food, its response was scored as correct. When a rat pulled up the string without food, its response was scored as incorrect. A response was also scored as incorrect if a rat pulled up the incorrect string at least half way. Both strings were removed at the end of each trial. The rats received 20 trials per day, and testing was stopped when they achieved a performance score of at least $90 \%$ (18 of 20 trials) on 2 consecutive days.

Acquisition. The rats were presented with two strings simultaneously on each trial; one of them contained food. The rats were to identify the string containing food by using a compound of two separate cues: string size and string odor (Figure 1). The string sizes were $\mathrm{T} 1$ and $\mathrm{T} 2$, and the odors were almond extract present $(\mathrm{O} 1)$ and almond extract absent $(\mathrm{O} 2)$. Four stimulus compounds were thus possible $(<\mathrm{T} 1-\mathrm{O} 1\rangle,\langle\mathrm{T} 1-\mathrm{O} 2\rangle,\langle\mathrm{T} 2-\mathrm{O} 1\rangle$, and $\langle\mathrm{T} 2-\mathrm{O} 2\rangle)$, and four pairings of these stimulus compounds were possible $(<\mathrm{T} 1-01>-<\mathrm{T} 1-$ $\mathrm{O} 2\rangle,\langle\mathrm{T} 1-\mathrm{O} 1\rangle-<\mathrm{T} 2-\mathrm{O} 1\rangle,\langle\mathrm{T} 2-\mathrm{O} 2\rangle-<\mathrm{T} 2-\mathrm{O} 1\rangle$, and $\langle\mathrm{T} 2-\mathrm{O} 2\rangle-$ $<\mathrm{T} 1-\mathrm{O} 2>$ ). For half of the rats in each group, the positive compounds were $\langle\mathrm{T} 1-\mathrm{O} 1\rangle$ and $\langle\mathrm{T} 2-\mathrm{O} 2\rangle$ and the negative compounds were $<\mathrm{T} 1-\mathrm{O} 2\rangle$ and $\langle\mathrm{T} 2-\mathrm{O} 1\rangle$. For the remaining rats, the positive compounds were $<\mathrm{T} 1-\mathrm{O} 2\rangle$ and $<\mathrm{T} 2-\mathrm{O} 1>$ and the negative compounds were $<\mathrm{T} 1-\mathrm{O} 1\rangle$ and $<\mathrm{T} 2-\mathrm{O} 2>$. The rats received 20 trials per day, five of each of the four compound pairings.

Training. Training took place in three stages. In Stage 1, two strings of the same size were used. The tape on one of the two strings was freshly coated with almond extract, and this cue indicated that the string was reinforced. The position of the reinforced string was varied from left to right via a pseudorandom, balanced sequence. In Stage 2, two strings of the other size were used; the negative string contained odor and the positive string contained no odor. The full complement of string pairings were given in Stage 3.

Retention after a break. After acquisition of the task, the 14 control rats received a 7 -day no-training break. They were then retrained on Stage 3. 
Postsurgical retention. The control rats tested for acquisition received thalamic lesions. Seven received lesions with quinolinic acid and 7 received lesions with ibotenic acid. Beginning a few days after surgery, the rats were retrained on Stage 3.

\section{Place Task}

Fifty-two rats were tested in the swimming pool: 24 control rats that had participated in preliminary string pulling tasks and 14 ibotenic acid and 14 quinolinic acid rats that were tested presurgically and postsurgically in the configural task (above).

The rats were placed in the pool facing the wall at one of four starting positions (east, north, south, or west). The latency to find the platform on each trial, which was timed with a stopwatch, and the swim path, drawn on a map of the pool, were used to assess performance. A trial terminated when a rat found the platform or after $60 \mathrm{sec}$ had elapsed. The rats were left on the platform for $10 \mathrm{sec}$, and were removed from the pool after each trial. Swim paths were rated on a 2-point scale. If a rat remained within an $18-\mathrm{cm}$ alley stretching from the start to the goal, its swim was considered correct and received a score of 0 ; if a rat left the alley, its swim was considered incorrect and received a score of 1 (Figure 7).

The rats were tested on 10 consecutive days. They were brought into the test room in groups of 2 to 7 . Each group consisted of a mix of control and thalamic rats, which were tested individually. There were eight different platform locations, with a different one being used each day (see Figure 7). The rats received eight trials per day, two from each of the four starting positions. Order of the starting positions was pseudorandom, but once a rat received a trial from a particular position it immediately received its second trial from that same position. It was then removed from the pool for approximately 5 min while other rats swam.

\section{Amphetamine-Induced Activity}

Data were collected from rats in the activity cages after they had completed water-maze testing. The counters failed on 3 control rats so that only 21 control rats were tested. Rats were placed in the activity cages individually for two sessions, and 3 to 5 days elapsed between sessions. During the first $2 \mathrm{~h}$ of each session, baseline activity measures were recorded. The rats were then injected with $d$ amphetamine subcutaneously under the neck $(1.25 \mathrm{mg} / \mathrm{kg}$ on the first test and $2.5 \mathrm{mg} / \mathrm{kg}$ on the second), and another $2 \mathrm{~h}$ of data were collected.

\section{Histology}

At the completion of behavioral testing, the rats were deeply anesthetized with sodium pentobarbital $(100 \mathrm{mg} / \mathrm{kg}$ i.p.) and were transcardially perfused with a $0.9 \%$ saline solution followed by $10 \%$ formalsaline. The brains were removed and stored in a $30 \%$ sucrose and $10 \%$ formal-saline solution. They were sectioned at $-20^{\circ} \mathrm{C}$ using a cryostat. Every third to fifth $40-\mu \mathrm{m}$-thick section throughout the thalamus was mounted on gelatin-coated glass slides. The sections were stained with cresyl violet and were examined microscopically.

\section{Relation Between Lesions and Performance}

The following analyses were done to see if lesion size was related to performance: (1) The area of the thalamus at three different planes was calculated by using an image-analyzing system. The planes were located $1.4,2.3$, and $3.8 \mathrm{~mm}$ posterior to bregma, respectively (Paxinos \& Watson, 1985). Correlations between the area measurements and behavior of the rats were then calculated. (2) The amount of damage to various thalamic nuclei was rated on the following scale: $0=$ completely gone, $0.5=$ very severe, $1=$ severe, $1.5=$ moderate, $2=$ mild, $2.5=$ very mild , and $3=$ not damaged. The rated nuclei included the anterior dorsal, anterior ventral, and anterior medial thalamic nuclei, the habenula, the lateral dorsal and lateral posterior thalamic nuclei, the medial dorsal thalamic nucleus, the ventral anterior lateral thalamic nucleus, the ventrobasal thalamic nuclei (i.e., the ventral posterior medial nucleus, the ventral posterior lateral nucleus, and the posterior thalamic complex), the stria medullaris, the paraventricular and paratenial thalamic nuclei, the centromedial, rhomboid, and reuniens thalamic nuclei, the submedial thalamic nucleus, the paracentral thalamic nucleus, and the claustrum. Correlations between the damage ratings and behavior of the rats were then calculated.

\section{Data Analysis}

The results were analyzed using analysis of variance (ANOVA), descriptive statistics, and correlation features of the statistical software package BMDP (Dixon, 1985), and Newman-Keuls follow-up tests (Winer, 1962). We report statistical details (ANOVAs and correlation coefficients) for results that are significant $(p<.050)$ : otherwise the results are reported as being nonsignificant.

\section{RESULTS}

\section{Histology}

The ibotenic acid lesions produced extensive damage to the MD as well as to adjacent nuclei. The average extent of the lesions is indicated by the shading in Figure 2 left, and an example of a typical lesion is shown in Figures 3B and 4B. Structures that received partial damage in addition to the MD included the stria medullaris, the lateral habenula, the medial edge of the central lateral nucleus, the paraventricular nucleus, the intermediodorsal nucleus, medial parts of the anterior dorsal and anterior ventral nuclei, the paratenial nucleus, the interanterodorsal nucleus, medial parts of the central medial and anteromedial nuclei, and dorsal parts of the rhomboid nucleus. Some of the lesions spread further laterally and ventrally to include medial parts of the lateral dorsal thalamic nucleus along with parts of the paracentral, ventral medial, submedial, and reuniens nuclei. Two of the rats had mild calcification. The medial habenula was intact in most rats. Some lesions were asymmetrical, sparing the most lateral components of the MD on one side or the other. Some sparing of the posterior and anterior poles of the MD was also observed (see Figures 2, 3, and 4). The quinolinic acid lesions were much larger than the ibotenic acid lesions, producing damage to many thalamic nuclei (Figure 2 right). Nuclei not completely damaged included the paraventricular and centromedial thalamic nuclei, which had some cells spared, and the reticular, ventral posterolateral, lateral edge of the ventral posteromedial and lateral edge of the lateral dorsal thalamic nuclei, which were entirely spared (Figures $3 \mathrm{C}$ and $4 \mathrm{C}$ ). Most of the quinolinic rats' lesions were inconsistent in that patches of cells were spared in many locations and structures throughout the thalamus contained large, dark granules, which, on the basis of anatomical work in previous studies (Whishaw, 1990), appeared to be calcium accumulations (Figures $3 \mathrm{C}$ and $4 \mathrm{C}$ ).

\section{Configural Task}

\section{Acquisition}

There were no significant differences between the control group and the thalamic groups on Stages 1 and 2 of the task, during which the animals had to learn the elements of the compound [Stage 1: trials, $F(2,25)=1.69, p=.210$, 

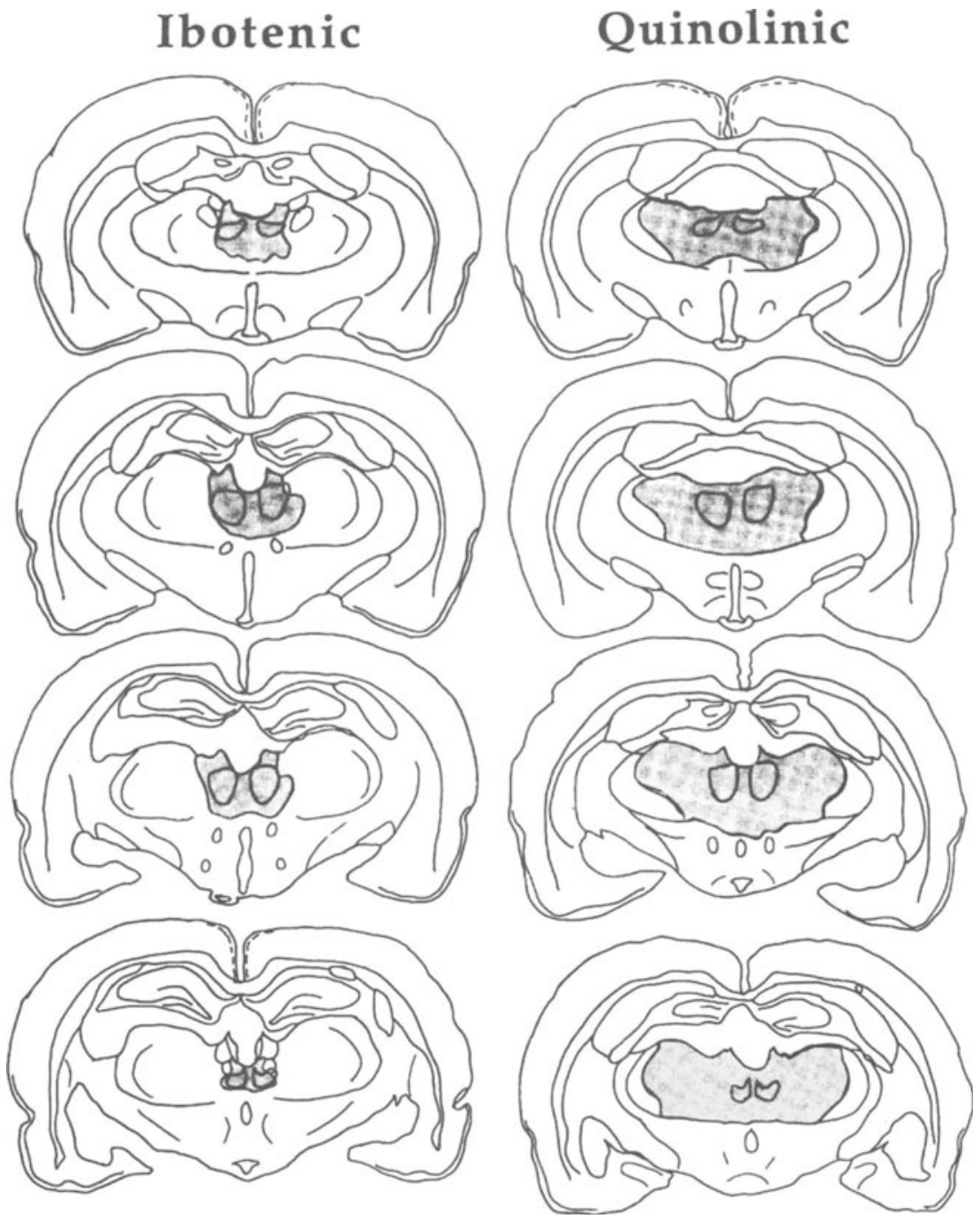

Figure 2. Tracings of coronal sections through the brains of rats that received ibotenic acid or quinolinic acid lesions. The shaded areas on the sections indicate the extent of thalamic damage as indicated by cell loss and gliosis. The location of dorsomedial thalamic nucleus is shown within the area of the lesion. Relative to bregma, anterior-posterior coordinates are: $-1.8,-2.8,-3.3$, and $-3.8 \mathrm{~mm}$ (Paxinos \& Watson, 1985).

and errors, $F(2,25)=1.50, p=.240$; Stage 2: trials, $F(2,25)=2.60, p=.090$, and errors, $F(2,25)=1.74, p=$ .196]. On Stage 3 , however, in which the animals had to learn the compound, there were significant differences [trials, $F(2.25)=4.45, p=.022$; errors, $F(2,25)=5.26, p=.012]$. Follow-up tests indicated that the ibotenic acid group was not significantly impaired relative to the control group, whereas the quinolinic group was significantly impaired on both trials and errors (Figure 5). Even though the impairment displayed by the quinolinic group was significant, all of the animals learned the task and 3 of the 7 fell within the control range of performance.

\section{Retention}

To evaluate performance on retention, the control rats were retested on the compound after a 7-day break, then given surgery and finally retested after 7 days of recovery. Their postsurgical performance was compared with their presurgical performance after the break. For both the measure of errors and the trials to acquisition, there were significant effects $[F \mathrm{~s}(1,12)>10, p \mathrm{~s}<.001]$, but the group receiving the quinolinic lesions performed significantly worse than the group receiving ibotenic lesions $[F(1,12)>8.00, p<.001]$ (Figure 6). The rats that received ibotenic acid lesions were only slightly impaired, whereas the group that received the quinolinic acid lesions displayed impairments as severe as those displayed upon initial acquisition $[F(1,12)>5, p<.01]$. An estimate of savings displayed by rats with ibotenic acid lesions relative to control initial acquisition scores was $70 \%$ for errors; the group that received quinolinic acid lesions displayed no savings. 

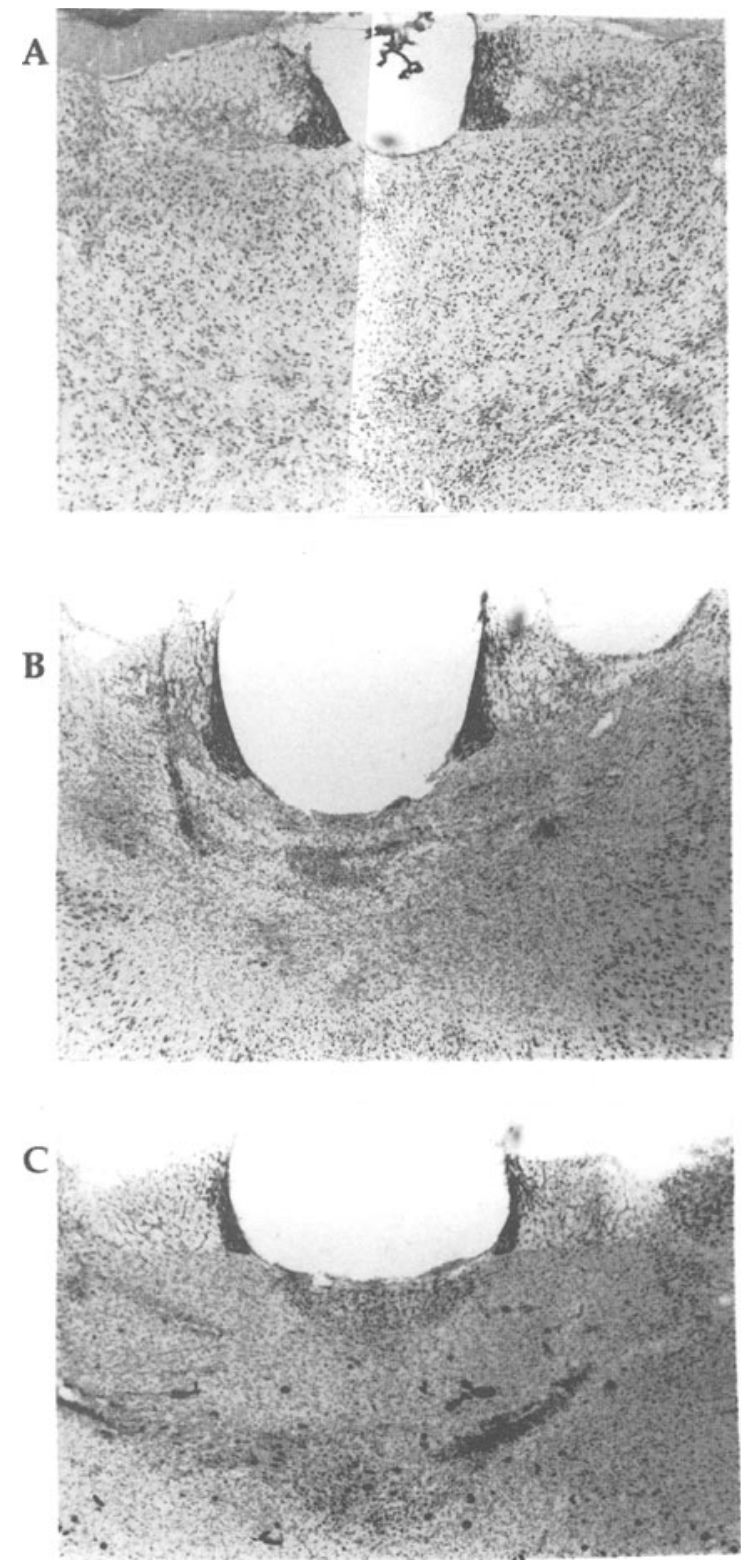

Figure 3. Photomicrographs of the dorsomedial thalamic nucleus of (A) a control rat, (B) an ibotenic rat, and (C) a quinolinic rat. Note the loss of cells in the two lesion sections. The black patches and large black dots in the quinolinic lesion are calcium deposits. $($ Cresyl violet; magnification $=\mathbf{5 0} \times$.

\section{Place Task}

All of the animals displayed improved performance across trials and problems in the place test [latency, $F(7,343)=123, p=.001$, errors, $F(7,343)=40.2, p<$ .001 ]. There were group differences on both measures [latency, $F(2,49)=6.06, p=.005$; errors, $F(2,49)=5.67$, $p=.006]$. Follow-up tests indicated that the control and ibotenic group were not different and that the ibotenic and quinolinic groups were not different, but that the perfor- mance of the quinolinic group was significantly poorer than that of the control group (Figure 7).

\section{Locomotor Activity}

In the tests of locomotor activity in the no-drug condition and after administration of two different doses of amphetamine, there were significant group, drug treatment, test time, and interaction effects (Figure 8). In the baseline no-drug tests (Figure 8, top), there were no group differences $[F(2,46)=0.04, p=.961]$, but there were differences across the 10 -min time bins $[F(11,506)=3.11, p<.001]$
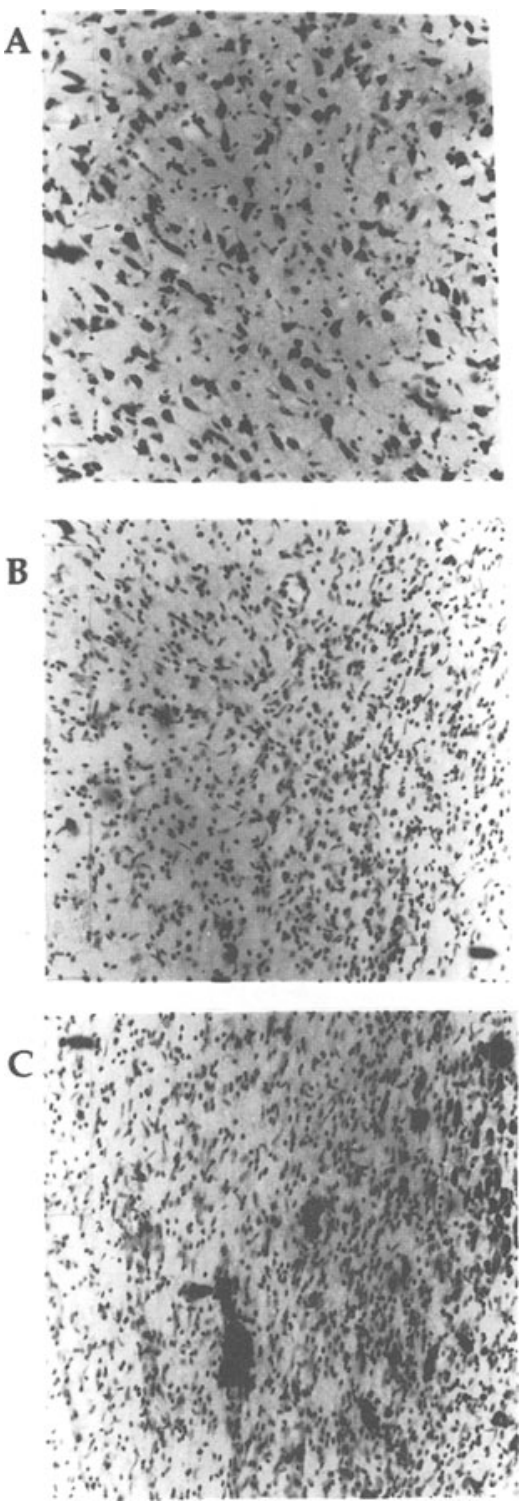

Figure 4. Photomicrographs of dorsomedial thalamic nucleus of (A) a control rat, (B) an ibotenic rat, and (C) a quinolinic rat. Note the cell loss and gliosis produced by the ibotenic and quinolinic acid and the calcification (large black patches) produced by the quinolinic acid. (Cresyl violet; magnification $=200 \times$.) 

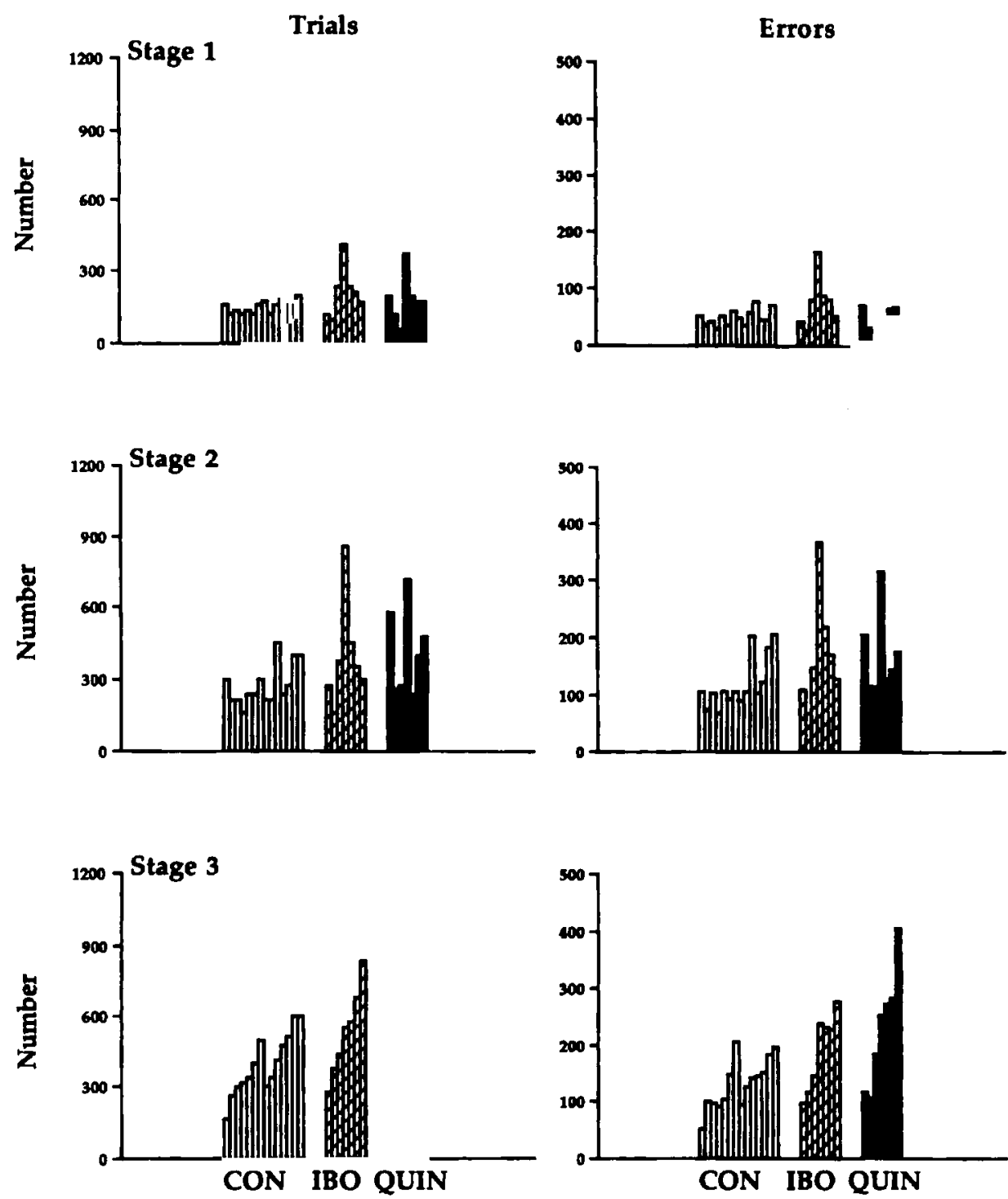

Figure 5. Total trials (left) and errors (right) by individual rats on Stage 1 (top), Stage 2 (middle), and Stage 3 (bottom) of the configural task. Stage 1 was a simple odor discrimination; on Stage 2, the odor discrimination was reversed; and on Stage 3, the compound was presented. The dorsomedial nucleus lesioned thalamic rats did not differ from controls on Stages 1 and 2, but the quinolinic acid group was impaired relative to the control group on Stage 3. The bars on the graphs are aligned by rat. (CON = control; IBO = ibotenic acid; QUIN = quinolinic acid.)

as animals in all groups were more active when initially placed into the activity cages than they were at the end of the 2-h session.

After administration of $1.25 \mathrm{mg} / \mathrm{kg}$ of amphetamine, all the groups became significantly more active, but there were no significant group differences (Figure 8 , middle). There was a group $\times$ time bin interaction $[F(22,506)=$ $2.39, p<.001]$, however, which follow-up tests indicated was due to differences between the activity profile of the control and quinolinic groups.

After administration of $2.5 \mathrm{mg} / \mathrm{kg}$ of amphetamine (Figure 8 , bottom), there were significant group $[F(2,46)=$ $6.59, p<.003]$ and time bin $[F(11,506)=21.61, p<.001]$ effects and a group $\times$ time bin interaction $[F(22,506)=$
$2.28, p<.001]$. Follow-up tests indicated that there were no differences in the activity levels of the control and ibotenic acid groups, but both of these groups were significantly less active than the quinolinic acid group.

\section{Correlations Between Thalamic Area and Behavior}

Correlation coefficients between MD lesion size and behavior for the ibotenic acid group were not significant. Cofrelation coefficients obtained between overall thalamic lesion size and behavior of the quinolinic acid group were significant $(p<.05)$ for configural task retention (trials and errors) and matching-to-place task latency. Configural task acquisition measures (trials and errors) were significantly correlated with ventral anterior lateral and pos- 

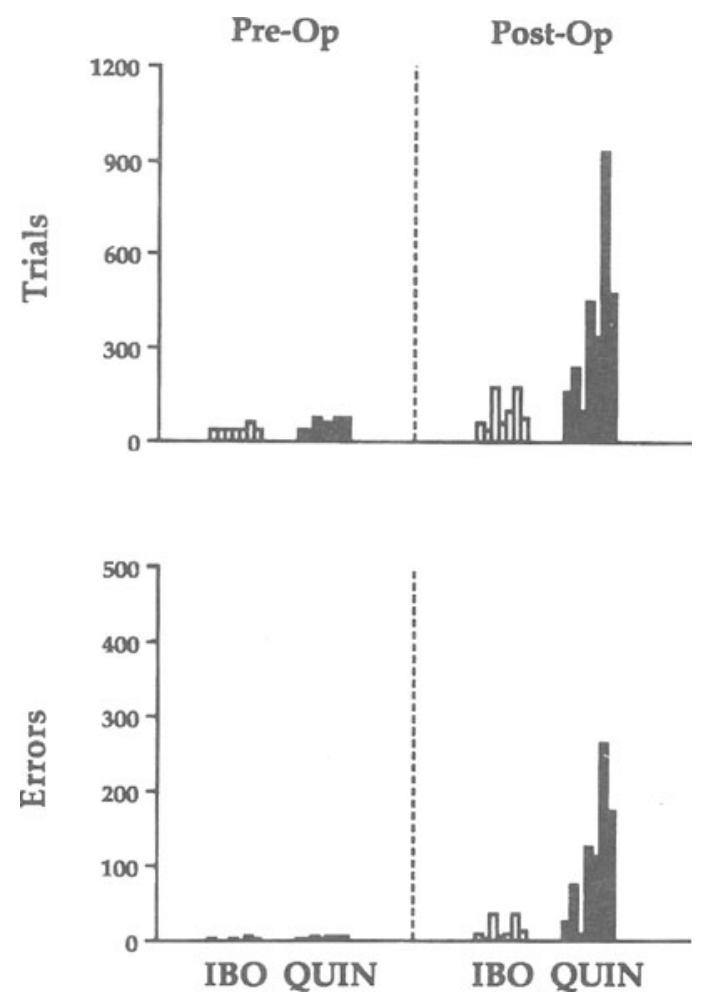

Figure 6. Total trials (top) and errors (bottom) of individual rats on Stage 3 of the configural task after a preoperative (PreOp) 7-day no-training break and after (Post-Op) intrathalamic infusions of ibotenic acid (IBO) or quinolinic acid (QUIN). Note the impaired postoperative performance of the rats and, in particular, that of the quinolinic rats. The bars on the graphs are aligned by rat.

terior thalamic complex damage. Configural task retention measures (trials and errors) were correlated with anterior ventral nucleus damage. Place task performance was correlated with anterior ventral, anterior medial, lateral dorsal, lateral posterior, paratenial, centromedial, rhomboid, and reuniens nuclei damage. Damage to the centromedial, rhomboid, and reuniens nuclei correlated significantly with activity after the low dose of amphetamine, but there were no significant correlations with behavior for any structure after the high dose of amphetamine. If it is considered that the ibotenic acid lesions were relatively homogeneous and restricted to MD, significant lesion size and behavior correlations would not be expected. If it is considered that the quinolinic acid lesions were relatively diffuse, the significant correlations may simply indicate that larger lesions are more likely to produce behavioral impairments.

\section{DISCUSSION}

This experiment was performed to assess whether MD played a role in acquiring tasks in which learning stimulus compounds was essential. The ibotenic acid lesions produced relatively complete and selective cell death in $\mathrm{MD}$, but did not produce impairments in learning or re- tention of a configural tactile-olfactory task or in learning a matching-to-place task in a swimming pool. Additionally, the lesions produced no changes in spontaneous or amphetamine-induced activity. The results show that although the frontal cortex and hippocampus, which MD connects, may be importantly involved in these tasks, MD does not appear to share a similar involvement.

Embedded within the configural task used in the present study were three kinds of learning tasks. In the first stage of training, an animal must make an odor discrimination; in the second stage of training, the animal must perform a reversal; and in the third stage of training, the ani-
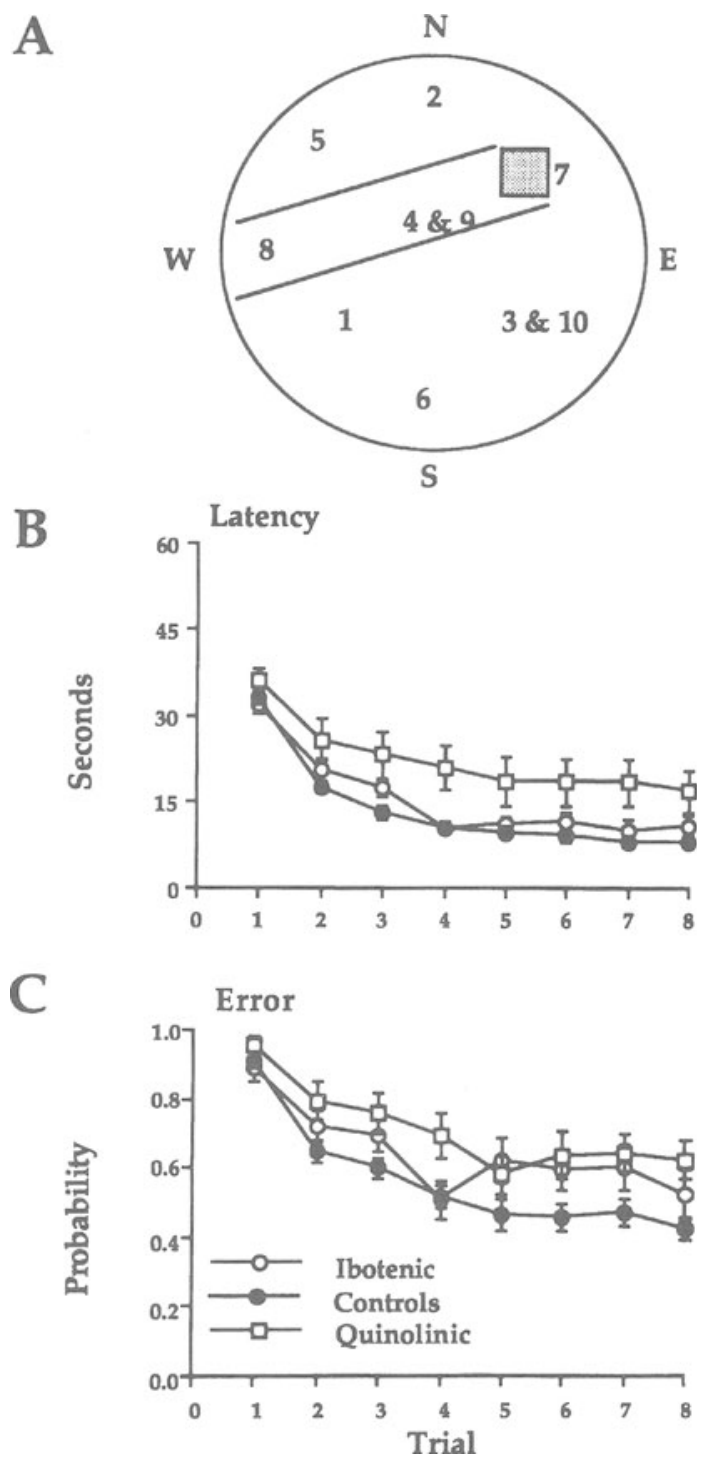

Figure 7. (A) The place task: Starting positions-north (N), south (S), east (E), or west (W) —and platform (shaded box). If a rat stayed within an 18-cm alley, indicated by lines on the diagram, the response is scored correct. Daily locations of the platform are represented by the numbers on the diagram. (B) Latencies (means and standard errors averaged across days). (C) Errors (means and standard errors averaged across days). 

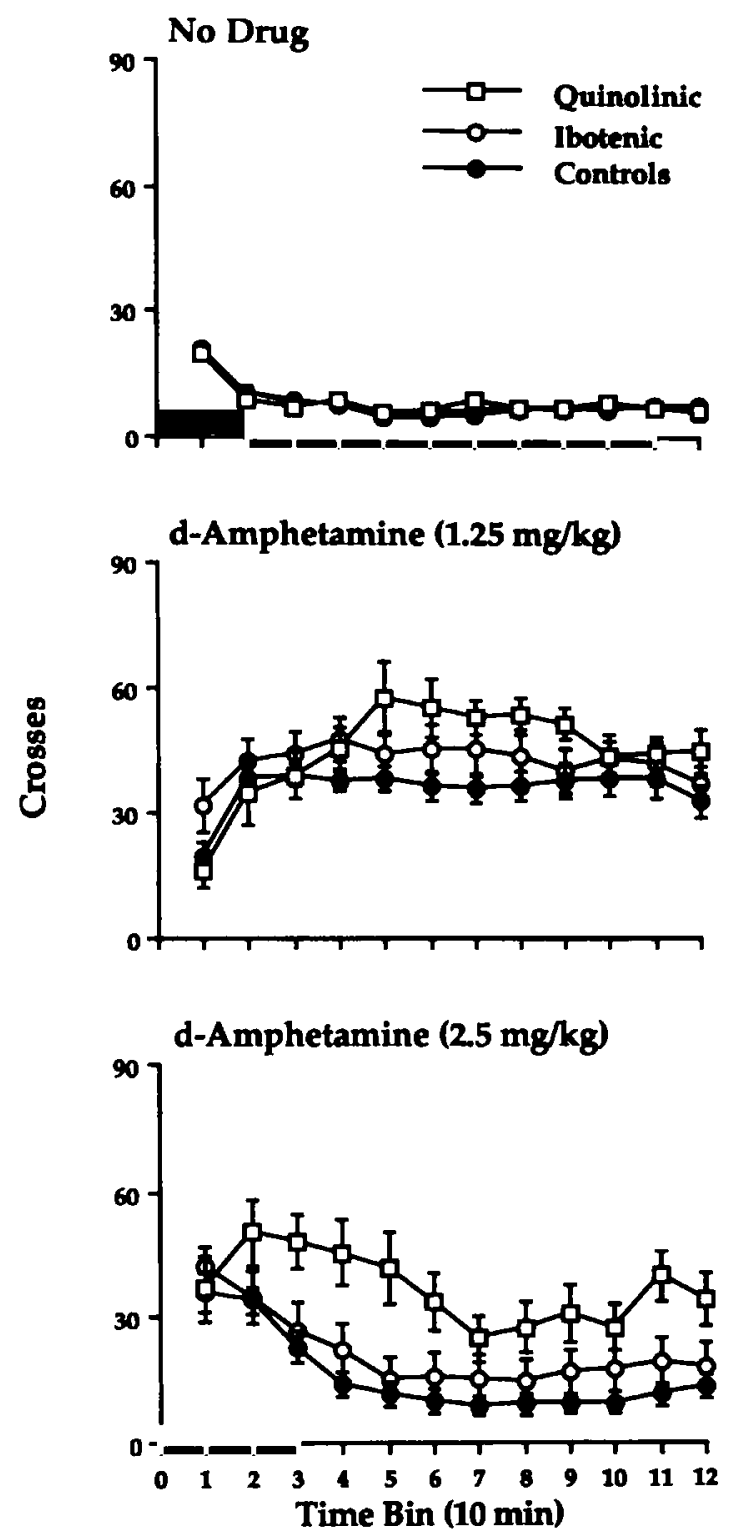

Figure 8. Crosses (means and standard errors) made by the rats in the activity cages during each of the 1210 -min-long time bins before drug administration (top) and after administration of $1.25 \mathrm{mg} /$ $\mathrm{kg} d$-amphetamine (middle) and $2.5 \mathrm{mg} / \mathrm{kg} d$-amphetamine (bottom).

mal learns a tactile-olfactory compound. The ibotenic acid MD lesions did not impair simple cue learning, learning of the reversal, or learning of the compound. When lesions were made after the compound had been learned, there was an impairment, but it was relatively slight and certainly not of a magnitude to suggest that the rats had to relearn the task. In some respects, these results are surprising, because MD receives olfactory projections and, in turn, projects to orbital or olfactory neocortex, where profound pre- and postoperative deficits are obtained on this configural task (Whishaw et al., 1992). Additionally, other work indicates that impairments on olfactory discrimina- tions and reversals can be obtained from lesions to MD (Eichenbaum et al., 1980; Slotnick \& Kaneko, 1981; Staubli et al., 1987). Thus, although MD may participate in some forms of learning that involve olfaction, these do not include simple odor detection, reversal, or use of odor in a compound with a cue from a different modality.

The rats with ibotenic acid MD lesions were also not impaired in learning a matching-to-place task in the swimming pool. This finding is consistent with our previous report that MD lesions do not impair acquisition of a simple place task (Kolb et al., 1982). The matching-to-place task is a special version of swimming-pool place tasks in that the animals are required to learn a new place problem each day. As rats acquire this task, they become so proficient that they acquire each new problem in one trial. That is, on the first trial, they must swim until they discover the location of the platform, but on the second trial, they swim directly to it (Whishaw, 1985). That rats with ibotenic acid MD lesions perform as well as control rats on this version of the task suggests that the lesions fully spare their spatial abilities. Rats with MD lesions have been reported to be impaired on dry-land spatial tasks in some studies (M'Harzi et al., 1991; Stokes \& Best, 1990b) but not in others (Kolb et al., 1982). At present, it is not known whether these differences are due to task differences, procedural differences, or lesion differences.

In contrast to the absence of impairments produced by the ibotenic acid lesions, the quinolinic acid lesions produced significant acquisition and retention deficits on the configural task and significant deficits on the matchingto-place spatial task. The quinolinic acid lesions, however, were not localized. They extended into many thalamic structures and also produced widespread deposits of calcium. Thus, it is not possible to ascertain whether the impairments that they produced were due to nonspecific damage of a large thalamic area (Vanderwolf, 1962) or to damage to some nuclei that are especially involved in the tasks on which the rats were tested. The lesions did extend into the lateral dorsal thalamus, and studies with lesions and single-cell recording have suggested a role for this structure in spatial behavior (Mizumori, Miya, \& Ward, 1994; Mizumori \& Williams, 1993). The lesions also damaged the internal medullary lamina of the thalamus, and studies on thiamine-deficient rats and rats with radiofrequency lesions suggest an association between damage to this structure and spatial learning (Koger \& Mair, 1994; Langlais, Mandel, \& Mair, 1992; Mair, Knoth, Rabchenuk, \& Langlais, 1991; Mair \& Lacourse, 1992). The lesions also extended into the anterior thalamic nucleus, which has connections with hippocampus and cingulate cortex and has also been shown to be involved in learning (Gabriel, Sparenborg, \& Stolar, 1987; Peinado-Manzano \& PozoGarcia, 1991).

In addition to the learning tasks, the rats were tested for spontaneous and amphetamine-induced locomotion. Damage to both the hippocampal formation (Whishaw \& Mittleman, 1991) and frontal cortex (Lynch et al., 1969) produce heightened locomotion under both conditions. The animals with ibotenic acid lesions did not differ from the con- 
trol rats when undrugged, and they displayed the same responses in locomotor activity observed in the control group following amphetamine, including increased locomotion at the lower dose and increased locomotion followed by stereotyped behavior at the higher dose (see Whishaw \& Mittleman, 1991). The rats that received quinolinic acid displayed heightened locomotion at both amphetamine doses. This response is similar to that observed in rats that have sustained frontal cortex (Lynch et al., 1969) and hippocampal formation lesions (Mittleman, LeDuc, \& Whishaw, 1993; Whishaw \& Mittleman, 1991). The impairments in learning and the increases in locomotion that are observed to follow lesions as widely placed as the fimbria-fornix and thalamus are intriguing not only because they confirm a relation between exploratory locomotor changes and changes in learning (O'Keefe \& Nadel, 1978 ), but also because they might be taken as a suggestion that the quinolinic acid lesions did damage some thalamic structure that is involved in the control of both exploratory activity and learning.

In summary, the objective of this study was to examine whether MD participated in learning that involves forming cue compounds to guide responses, and especially, given its olfactory projection to orbital frontal cortex, whether it is involved in learning compounds involving olfactory cues. Ibotenic acid lesions were found to produce extensive cell loss in MD but no changes in performance on a configural tactile-olfactory task, a matching-to-place task in a swimming pool, or spontaneous and amphetamineinduced locomotion. Quinolinic acid lesions produced extensive cell loss and calcium deposits throughout the thalamus as well as impairments in all of the behavioral tasks. The results suggest that MD does not participate in the learning of tasks involving cue compounds and also that large lesions can impair learning (Mair, Robinson, Koger, Fox, \& Zhang, 1992), or that one or a number of thalamic nuclei may be involved both in learning and in the control of locomotion. Although a number studies suggest that frontal cortex and possibly MD may be involved in tasks in which there is a working memory component (Fuster, 1989; Goldman-Rakic, 1990; Mumby et al., 1993) or in which species-typical behaviors are measured (Kolb, 1977), these functions were not demand characteristics of the tasks used in the present study. Thus, the results of this study are silent on the specific features of behavior for which MD is essential.

\section{REFERENCES}

AgGleton, J. P., \& MishKin, M. (1983a). Memory impairments following restricted medial thalamic lesions in monkeys. Experimental Brain Research, 52, 199-209.

AGGLETON, J. P., \& MisHKIN, M. (1983b). Visual recognition impairments following medial thalamic lesions in monkeys. Neuropsychologia, 21, 189-197.

Alexander, G. E., Crutcher, M. D., \& DeLong, M. R. (1990). Basal ganglia-thalamocortical circuits: Parallel substrates for motor, oculomotor, "prefrontal" and "limbic" functions. In H. B. M. Uylings, C. G. Van Eden, J. P. C. De Bruin, M. A. Corner, \& M. G. P. Feenstra (Eds.), The prefrontal cortex: Its structure, function and pathology (Progress in Brain Research, Vol. 85, pp. 119-146.) Amsterdam: Elsevier.

Benjamin, R. M., \& JACKson, J. C. (1974). Unit discharges in the mediodorsal nucleus of the squirrel monkey evoked by electrical stimulation of the olfactory bulb. Brain Research, 7, 221-231.

CORwin, J. V., Fussinger, M., MEYer, R. C., KING, V. R., \& REEP, R. L. (1994). Bilateral destruction of the ventrolateral orbital cortex produces allocentric but not egocentric spatial deficits in rats. Behavioural Brain Research, 61, 79-86.

DELACOUR, J. (1971). Effects of medial thalamic lesions in the rat. A review and an interpretation. Neuropsychologia, 9, 157-174.

Dixon, W. J. (ED.) (1985). BMDP statistical software. Berkeley: University of California Press.

DunnetT, S. B., WhishaW, I. Q., Jones, G., \& BunCh, T. (1987). Behavioral, biochemical and histological effects of different neurotoxic amino acids injected into nucleus basalis magnocellularis of rats. Neuroscience, 20, 653-669.

Eichenbaum, H., Shedlack, K. L., \& EckmanN, K. W. (1980). Thalamocortical mechanisms in odor-guided behavior. I. Effects of lesions of the mediodorsal thalamic nucleus and frontal cortex on olfactory discrimination in the rat. Brain, Behavior \& Evolution, 17, 255-275. Fuster, J. M. (1989). The prefrontal cortex. New York: Raven Press. Gabriel, M., SParenborg, S. P., \& Stolar, N. (1987). Hippocampal control of cingulate cortical and anterior thalamic information processing during learning in rabbits. Experimental Brain Research, 67, $131-152$

Goldman-RAKIC, P. S. (1990). Cellular and circuit basis of working memory in prefrontal cortex of nonhuman primates. In H. B. M. Uylings, C. G. Van Eden, J. P. C. De Bruin, M. A. Corner, \& M. G. P. Feenstra (Eds.), The prefrontal cortex: Its structure, function and pathology (Progress in Brain Research, Vol. 85, pp. 325-336). Amsterdam: Elsevier

Graff-Radford, N. R., Tranel, D., Van Hoesen, G. W., \& Brandt, J. P. (1990). Diencephalic amnesia. Brain, 113, 1-25.

HARVEY, V. I. (1967). Macrame: The art of creative knotting. New York: Van Nostrand.

Heimer, L. (1972). The olfactory connections of the diencephalon in the rat: An experimental light and electron microscopic study with special emphasis on the problem of terminal degeneration. Brain, Behavior \& Evolution, 6, 484-523.

Kessler, J., Markowitsch, H. J., \& OtTo, B. (1982). Subtle but distinct impairments of rats with chemical lesions in the thalamic mediodorsal nucleus and the ventral tegmental area in the rat. Behavioral Brain Research, 3, 125-130.

KogER, S. M., \& MAIR, R. G. (1994). Comparison of the effects of frontal cortical and thalamic lesions on measures of olfactory learning and memory in the rat. Behavioral Neuroscience, 108, 1088-1100.

KoLB, B. (1977). Studies on the caudate-putamen and the dorsomedial thalamic nucleus of the rat: Implications for mammalian frontal lobe functions. Physiology \& Behavior, 18, 237-244.

Kolb, B., Pittman, K., Sutherland, R. J., \& Whishaw, I. Q. (1982) Dissociations of the contribution of the prefrontal cortex and dorsomedial thalamic nucleus to spatially guided behavior in the rat. $B e$ havioral Brain Research, 6, 365-378.

LANGlais, P. J., MANDEl, R. J., \& MAIR, R. G. (1992). Diencephalic lesions, learning impairments, and intact retrograde memory following acute thiamine deficiency in the rat. Behavioral Brain Research, $\mathbf{4 8}$, $177-185$

Lynch, G., Ballantine, P., \& Campbell, B. A. (1969). Potentiation of behavioral arousal following cortical damage and subsequent recovery. Experimental Neurology, 23, 195-206.

Mair, R. G., KNoth, R. L., Rabchenuk, S. A., \& Langlais, P. J. (1991). Impairment of olfactory, auditory, and spatial learning in rats recovered from pyrithiamine-induced thiamine deficiency. Behavioral Neuroscience, 105, 360-374.

MAIR, R. G., \& LACOURSE, D. M. (1992). Radio-frequency lesions of the thalamus produce delayed-nonmatching-to-sample impairments comparable to pyrithiamine-induced encephalopathy in rats. Behavioral Neuroscience, 106, 634-645.

Mair, R. G., Robinson, J. K., Koger, S. M., Fox, G. D., \& Zhang, Y. P. (1992). Delayed-nonmatching-to-sample performance is impaired by extensive, but not by limited, lesions of the thalamus in the rat. $B e$ havioral Neuroscience, 106, 645-656.

M'Harzi, M., Jarrard, L. E., Willig, F., Palacios, A., \& DelaCOUR, J. (1991). Selective fimbria and thalamic lesions differentially 
impair forms of working memory. Behavioral \& Neural Biology, 56, 221-239.

Mittleman, G., LeDuc, P., \& Whishaw, I. Q. (1993). The role of D1 and $\mathrm{D} 2$ receptors in the heightened locomotion induced by direct and indirect dopamine agonists in rats with hippocampal damage: An animal analogue of schizophrenia. Behavioral Brain Research, 55, 253-267.

Mizumori, S. J., MiYA, D. Y., \& WARD, K. E. (1994). Reversible inactivation of the lateral dorsal thalamus disrupts hippocampal place representation and impairs spatial learning. Brain Research, 644, 168-174.

Mizumori, S. J., \& Williams, J. D. (1993). Directionally selective mnemonic properties of neurons in the lateral dorsal nucleus of the thalamus of rats. Journal of Neuroscience, 13, 4015-4028.

Mogenson, G. J., Jones, D. L., \& YIM, C. Y. (1980). From motivation to action: Functional interface between the limbic system and the motor system. Progress in Neurobiology, 14, 69-97.

MoRRIS, R. G. M. (1981). Spatial localization does not require the presence of local cues. Learning \& Motivation, 12, 239-260.

Mumby, D. G., Pinel, J. P. J., \& DAstur, F. N. (1993). Mediodorsal thalamic lesions and object recognition in rats. Psychobiology, 21, 27-36.

O'KEEFE, J., \& NADEL, L. (1978). The hippocampus as a cognitive map. Oxford: Oxford University Press, Clarendon Press.

PAXINOS, G., \& WATSON, C. (1985). The rat brain in stereotaxic coordinates. Sydney: Academic Press.

Peinado-Manzano, M. A., \& Pozo-Garcia, R. (1991). The role of different nuclei of the thalamus in processing episodic information. $B e-$ havioral Brain Research, 45, 17-27.

Petri, H. L., \& Mishkin, M. (1994). Behaviorism, cognitivism and the neuropsychology of memory. American Scientist, 82, 28-37.

RICHTER, C. P. (1976). The psychobiology of Curt Richter. Baltimore: York Press.

RudY, J. W., \& Sutherland, R. J. (1992). Configural and elemental associations and the memory coherence problem. Journal of Cognitive Neuroscience, 4, 208-216.

SLotnick, B. M., \& KaneKo, N. (1981). Role of the mediodorsal thalamic nucleus in olfactory discrimination learning in rats. Science, 214, 91-92.

SQUiRE, L. R., \& Moore, R. Y. (1979). Dorsal thalamic lesion in a noted case of human memory dysfunction. Annals of Neurology, 6, 503-506.

Staubli, U., Schottler, F., \& Nejat-Bina, D. (1987). Role of dorsomedial thalamic nucleus and piriform cortex in processing olfactory information. Behavioral Brain Research, 25, 117-129.

STOKES, K. A., \& BeST, P. J. (1990a). Mediodorsal thalamus lesions in rats impair radial-arm maze performance in a cued environment. $P s y$ chobiology, 18, 63-67.

STOKES, K. A., \& BeST, P. J. (1990b). Mediodorsal thalamus lesions impair "reference" and "working" memory in rats. Physiology \& Behavior, 47, 471-476.

SutherLand, R. J., \& RUdy, J. W. (1989). Configural association theory: The role of the hippocampal formation in learning, memory, and amnesia. Psychobiology, 17, 129-144.
Tinger, J. C. (1974). The effects of dorsomedial thalamic lesion on learning, reversal, and alternation behavior in the rat. Physiology \& Behavior, 12, 13-17.

Tomie, J., \& WhishaW, I. Q. (1990). New paradigms for tactile discrimination studies with the rat: Methods for simple, conditional, and configural discriminations. Physiology \& Behavior, 48, 225-231.

VANDERWOLF, C. H. (1962). Medial thalamic functions in voluntary behaviour. Canadian Journal of Psychology, 16, 318-330.

Victor, M., Adams, R. D., \& Collins, G. H. (1971). The WernickeKorsakoff syndrome. Oxford: Blackwell.

WhISHAW, I. Q. (1985). Cholinergic receptor blockade in the rat impairs locale but not taxon strategies for place navigation in a swimming pool. Behavioral Neuroscience, 99, 979-1005.

WHISHAW, I. Q. (1987). Hippocampal granule cell and CA 3-4 lesions impair formation of a place learning-set in the rat and induce reflex epilepsy. Behavioral Brain Research, 24, 59-72.

Whishaw, I. Q. (1990). The decorticate rat. In B. Kolb \& R. C. Tees (Eds.), The cerebral cortex of the rat (pp. 239-268). Cambridge, MA MIT Press.

Whishaw, I. Q., Cassel, J.-C., \& JarRard, L. E. (1995). Rats with fimbria-fornix lesions display a place response in a swimming pool: A dissociation between getting there and knowing where. Journal of Neuroscience, 15, 5779-5788.

Whishaw, I,Q., \& MitTLEMAN, G. (1991). Hippocampal modulation of the nucleus accumbens: Behavioral evidence from amphetamineinduced activity profiles. Behavioral \& Neural Biology, 55, 289-306.

WhishaW, I. Q., RoD, M. R., \& AUER, R. N. (1994). Behavioral deficits revealed by multiple tests in rats with ischemic damage limited to half of the CA1 sector of the hippocampus. Brain Research Bulletin, 34, 283-289.

Whishaw, I. Q., \& Tomie, J. (1991). Acquisition and retention by hippocampal rats of simple, conditional, and configural tasks using tactile and olfactory cues: Implications for hippocampal function. Behavioral Neuroscience, 105, 787-797.

WhishaW, I. Q., TomiE, J., \& KolB, B. (1992). Ventrolateral prefrontal cortex lesions in rats impair the acquisition and retention of a tactileolfactory configural task. Behavioral Neuroscience, 106, 597-603.

WINER, B. J. (1962). Statistical principles in experimental design. New York: McGraw-Hill.

WinOCUR, G. (1985). The hippocampus and thalamus: Their roles in short- and long-term memory and the effects of interference. Behavioral Brain Research, 16, 135-152.

Zola-Morgan, S., \& SQUIRE, L. R. (1985). Amnesia in monkeys following lesions of the mediodorsal nucleus of the thalamus. Annals of Neurology, 17, 558-564.

(Manuscript received July 31, 1995; revision accepted for publication October 11,1995 .) 